\title{
N-Terminal Pro-B-Type Natriuretic Peptide Is Not a Significant Predictor of Stroke Incidence After 5 Years
} - The Ohasama Study -

Michihiro Satoh, PhD; Takahisa Murakami, PhD; Kei Asayama, MD, PhD; Takuo Hirose, PhD; Masahiro Kikuya, MD, PhD; Ryusuke Inoue, MD, PhD; Megumi Tsubota-Utsugi, PhD; Keiko Murakami, PhD; Ayako Matsuda, PhD; Azusa Hara, PhD; Taku Obara, PhD; Ryo Kawasaki, MD, PhD; Kyoko Nomura, MD, PhD; Hirohito Metoki, MD, PhD; Koichi Node, MD, PhD; Yutaka Imai, MD, PhD; Takayoshi Ohkubo, MD, PhD

\begin{abstract}
Background: N-terminal pro-B-type natriuretic peptide (NT-proBNP) has been used for risk stratification in heart failure or acute coronary syndrome, but the beyond 5-year predictive value of NT-proBNP for stroke remains an unsettled issue in Asian patients. The aim of the present study was to clarify this point.

Methods and Results: We followed 1,198 participants (33.4\% men; mean age, $60.5 \pm 11.1$ years old) in the Japanese general population for a median of 13.0 years. A first stroke occurred in 93 participants. Referencing previous reports, we stratified participants according to NT-proBNP $30.0,55.0$, and $125.0 \mathrm{pg} / \mathrm{mL}$. Using the NT-proBNP $<30.0 \mathrm{pg} / \mathrm{mL}$ group as a reference, adjusted HR for stroke $(95 \% \mathrm{Cl})$ in the NT-proBNP $30.0-54.9-\mathrm{pg} / \mathrm{mL}, 55.0-124.9-\mathrm{pg} / \mathrm{mL}$, and $\geq 125.0-\mathrm{pg} / \mathrm{mL}$ groups were 1.92 (0.94-3.94), 1.77 (0.85-3.66), and $1.99(0.86-4.61)$, respectively. With the maximum follow-up period set at 5 years, the hazard ratio of the NT-proBNP $\geq 125.0-\mathrm{pg} / \mathrm{mL}$ group compared with the <30.0-pg/mL group increased significantly (HR, 4.51; 95\% Cl: 1.03-19.85). On extension of the maximum follow-up period, however, the association between NT-proBNP and stroke risk weakened.
\end{abstract}

Conclusions: NT-proBNP was significantly associated with an elevated stroke risk. Given, however, that the predictive power decreased with the number of years after NT-proBNP measurement, NT-proBNP should be re-evaluated periodically in Asian patients.

Key Words: Epidemiology; N-terminal pro-B-type natriuretic peptide; Prevention; Stroke

$\mathbf{N}$ -terminal pro-B-type natriuretic peptide (NTproBNP) is a stable $\mathrm{N}$-terminal fragment of B-type natriuretic peptide (BNP) and is a useful tool for risk stratification in heart failure or acute coronary syndrome. ${ }^{1-4}$ Moreover, NT-proBNP is considered a more sensitive marker of cardiac dysfunction than BNP. ${ }^{5}$
Although NT-proBNP has not been used for stroke risk stratification until now, a previous meta-analysis with a mean follow-up duration of 5 years reported the significance of NT-proBNP or BNP in stroke risk prediction. ${ }^{6}$ An association of NT-proBNP or BNP with an increased risk for cardiovascular disease was significant even after

Received November 7, 2017; revised manuscript received April 17, 2018; accepted April 19, 2018; released online June 9 , 2018 Time for primary review: 42 days

Division of Public Health, Hygiene and Epidemiology (M.S., T.M., H.M.), Division of Nephrology and Endocrinology (T.H.), Faculty of Medicine, Tohoku Medical and Pharmaceutical University, Sendai; Division of Aging and Geriatric Dentistry, Department of Oral Function and Morphology, Tohoku University Graduate School of Dentistry, Sendai (T.M.); Department of Hygiene and Public Health, Teikyo University School of Medicine, Tokyo (K.A., K.M., A.M., T. Ohkubo); Tohoku Institute for Management of Blood Pressure, Sendai (K.A., H.M., Y.I., T. Ohkubo); Department of Preventive Medicine and Epidemiology (M.K., T. Obara), Department of Community Medical Supports (H.M.), Tohoku Medical Megabank Organization, Tohoku University, Sendai; Department of Medical Information Technology Center (R.I.), Department of Pharmaceutical Sciences (T. Obara), Tohoku University Hospital, Sendai; Department of Hygiene and Preventive Medicine, Iwate Medical University School of Medicine, Morioka (M.T.-U.); Department of Social Pharmacy and Public Health, Showa Pharmaceutical University, Tokyo (A.H.); Department of Vision Informatics (Topcon), Osaka University Graduate School of Medicine, Suita (R.K.); Department of Public Health, Yamagata University Graduate School of Medical Science, Yamagata (R.K.); Department of Public Health, Akita University Graduate School of Medicine, Akita (K. Nomura); and Department of Cardiovascular Medicine, Saga University, Saga (K. Node), Japan

Mailing address: Michihiro Satoh, PhD, Division of Public Health, Hygiene and Epidemiology, Faculty of Medicine, Tohoku Medical and Pharmaceutical University, 1-15-1 Fukumuro, Miyagino-ku, Sendai 983-8536, Japan. E-mail: satoh.mchr@gmail. com

ISSN-1346-9843 All rights are reserved to the Japanese Circulation Society. For permissions, please e-mail: cj@j-circ.or.jp 


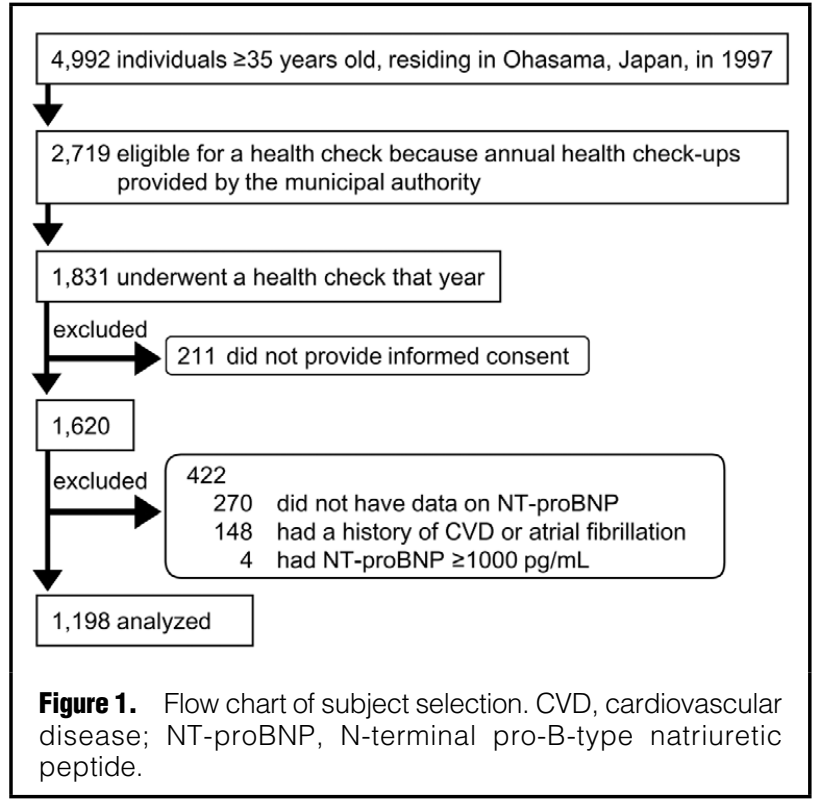

stratifying the available studies by the follow-up period of 5 years. ${ }^{6}$ Most of the available studies, however, have been conducted in non-Asian patients with elevated cardiovascular risk factors or stable cardiovascular disease. ${ }^{6}$ There have been no studies on the long-term predictive value of NT-proBNP for stroke in an Asian general population. ${ }^{6}$

Stroke incidence accounts for a substantial portion of total cardiovascular disease in Asian patients. ${ }^{7,8}$ Stroke prevention is a public health priority, especially in Asian countries. The Hisayama study followed up Japanese residents for 5 years, and found an elevated stroke risk in those with NT-proBNP $\geq 125.0 \mathrm{pg} / \mathrm{mL} .{ }^{9}$ The predictive value of NT-proBNP beyond 5 years, however, remains an unsettled issue in an Asian patients.

The aim of the present study was therefore to assess the long-term predictive value of NT-proBNP for stroke events using a follow-up period of 5 years as a stratifier. We adjusted the models for competing risks for death given that NT-proBNP has been reported to be associated with all-cause mortality. ${ }^{10}$

\section{Methods}

\section{Design}

This report is part of the Ohasama study, an ongoing cohort study started in 1986 . We have previously described the socioeconomic and demographic characteristics of this region and the details of the Ohasama study. ${ }^{11-13}$ This study conforms to the Helsinki declaration. The Institutional Review Boards of Teikyo University, Tohoku Medical and Pharmaceutical University and Tohoku University approved the study protocol.

\section{Subjects}

The flow chart of participant selection is shown in Figure 1. We used data from municipal annual health check-ups. The population of Ohasama in 1997 was 7,318, and 4,992 inhabitants were aged $\geq 35$ years old. Of the latter number, 2,719 were eligible for a health check because annual health check-ups provided by the municipal authority are available for farmers, the self-employed, pensioners, and dependents aged $\geq 35$ years in Japan. In total, 1,831 individuals underwent a health check that year, and 1,620 individuals (mean age, 61.6 \pm 11.3 years; male, 33.3\%) provided written informed consent to participate in the study. We excluded 422 participants from analysis because, at enrollment, they either did not have data on NT-proBNP $(n=270)$, or had a history of cardiovascular disease or atrial fibrillation $(\mathrm{AF} ; \mathrm{n}=148)$, which considerably affects NT-proBNP, ${ }^{14}$ or had NT-proBNP $\geq 1,000 \mathrm{pg} / \mathrm{mL} \quad(\mathrm{n}=4)$. Thus, the total number of participants analyzed was 1,198 .

\section{Data Collection}

Blood was collected in chilled EDTA tubes, and NTproBNP was determined using an electrochemiluminescence immunoassay (Roche Diagnostics, Tokyo, Japan). The intra- and inter-assay coefficients of variation for NTproBNP were $1.9 \%$ at $64 \mathrm{pg} / \mathrm{mL}$ and $3.1 \%$ at $46 \mathrm{pg} / \mathrm{mL}$, respectively. Information on smoking status and alcohol consumption, antihypertensive medication, and a history of diabetes mellitus, hypercholesterolemia, and cardiovascular disease was confirmed, based on medical records and a questionnaire. Smoking status and alcohol consumption were dichotomized as current or former/never. Hypercholesterolemia was defined as total cholesterol $\geq 5.7 \mathrm{mmol} / \mathrm{L}$ $(\geq 220 \mathrm{mg} / \mathrm{dL})$, using medication to treat hypercholesterolemia, and/or a history of hypercholesterolemia. Diabetes mellitus was defined as random blood glucose $\geq 11.1 \mathrm{mmol} / \mathrm{L}$ ( $\geq 200 \mathrm{mg} / \mathrm{dL}$ ), hemoglobin A1c $\geq 6.5 \%$ according to the Japan Diabetes Society, treatment with insulin or oral hypoglycemic agents, and/or a history of diabetes mellitus. ${ }^{15}$ Trained nurses at local medical centers measured blood pressure twice, using a semi-automatic blood pressure measuring device (USM-700F; UEDA Electronic Works, Tokyo, Japan), based on the microphone method, with participants in a seated position after resting for $\geq 2 \mathrm{~min}$, and maintaining the cuff position at heart level. ${ }^{16,17}$ The mean of the 2 readings was used in this analysis. Habitual exercise and daily sleep hours were investigated via selfadministered questionnaire. A lower level of habitual physical activity was defined as $\leq 1-2 \mathrm{~h}$ per week. Short sleep time was defined as $<6 \mathrm{~h}$ per day, and long sleep time as $>8 \mathrm{~h}$ per day.

\section{Follow-up and Outcome}

Resident registration cards confirmed residence in Ohasama (as of 30 November 2010). These cards are used for pensions and social security benefits and, therefore, are considered accurate and reliable. The incidence of stroke up until 30 November 2010, was determined via review of the Stroke Registration System of Iwate Prefecture, death certificates, National Health Insurance receipts, and questionnaires sent to each household at the time of health check-up. Almost all stroke cases were confirmed on magnetic resonance imaging and/or computed tomography of the brain. The diagnostic criteria of stroke subtypes were based on the Classification of Cerebrovascular Disease III of the National Institute of Neurological Disorders and Stroke. ${ }^{18}$ We did not consider transient ischemic attack as stroke in the present study.

\section{Statistical Analysis}

Participants were stratified according to NT-proBNP $55.0 \mathrm{pg} / \mathrm{mL}$ and $125.0 \mathrm{pg} / \mathrm{mL} .^{\mathbf{5 , 9 , 1 9}}$ Because approximately $60 \%$ of the present participants had NT-proBNP $<55 \mathrm{pg} / \mathrm{mL}$, 


\begin{tabular}{|c|c|c|c|c|c|}
\hline \multirow{2}{*}{ Variables } & \multicolumn{4}{|c|}{ NT-proBNP (pg/mL) } & \multirow{2}{*}{ P-value } \\
\hline & $<30.0(n=383)$ & $30.1-54.9(n=340)$ & $55.0-124.9(n=330)$ & $\geq 125.0(n=145)$ & \\
\hline Men & 46.0 & $24.4^{*}$ & $27.6^{\star}$ & $34.5^{\star}$ & $<0.0001$ \\
\hline Age (years) & $54.9 \pm 10.1$ & $59.1 \pm 10.4^{*}$ & $63.7 \pm 9.5^{*}$ & $71.0 \pm 8.6^{*}$ & $<0.0001$ \\
\hline BMI $\left(\mathrm{kg} / \mathrm{m}^{2}\right)^{\dagger}$ & $24.2 \pm 3.0$ & $23.6 \pm 3.2^{*}$ & $23.6 \pm 3.2^{*}$ & $22.9 \pm 3.7^{*}$ & 0.0008 \\
\hline Current smoking & 21.4 & $12.4^{*}$ & $12.7^{\star}$ & $13.8^{\star}$ & 0.0018 \\
\hline Alcohol consumption & 45.4 & $31.8^{*}$ & $31.5^{\star}$ & $26.2^{*}$ & $<0.0001$ \\
\hline Diabetes & 9.1 & 6.2 & 8.2 & 6.2 & 0.42 \\
\hline Hyperlipidemia & 30.3 & 26.8 & $21.2^{*}$ & $18.6^{*}$ & 0.0083 \\
\hline CKD & 6.0 & 6.5 & 8.8 & $22.8^{*}$ & $<0.0001$ \\
\hline $\mathrm{SBP}(\mathrm{mmHg})$ & $128.7 \pm 13.0$ & $129.9 \pm 12.5$ & $132.4 \pm 15.0^{\star}$ & $138.4 \pm 17.0^{\star}$ & $<0.0001$ \\
\hline $\mathrm{DBP}(\mathrm{mmHg})$ & $72.8 \pm 9.3$ & $73.2 \pm 8.6$ & $74.2 \pm 9.8^{\star}$ & $75.5 \pm 9.6^{\star}$ & 0.013 \\
\hline Antihypertensive drugs & 10.7 & $20.3^{*}$ & $33.0^{*}$ & $45.5^{\star}$ & $<0.0001$ \\
\hline NT-proBNP $(p g / m L)^{\ddagger}$ & $18.3(10.8-24.3)$ & $40.2(34.5-47.3)^{\star}$ & $77.1(65.3-92.6)^{\star}$ & $173.4(149.1-237.5)^{\star}$ & $<0.0001$ \\
\hline
\end{tabular}

Data given as mean $\pm \mathrm{SD}$, \% or median (IQR). ${ }^{*} \mathrm{P}<0.05$ vs. NT-proBNP $<30.0 \mathrm{pg} / \mathrm{mL}$ (t-test or chi-squared test). ${ }^{+D a t a}$ unavailable for 27

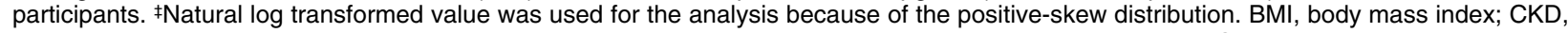
chronic kidney disease; DBP, diastolic blood pressure; NT-proBNP, N-terminal pro-B-type natriuretic peptide; SBP, systolic blood pressure.

we further stratified these participants into 2 groups using the approximate median NT-proBNP in that group, that is, NT-proBNP $<30 \mathrm{pg} / \mathrm{mL}$ and $\geq 30 \mathrm{pg} / \mathrm{mL}$.

To analyze the association between participant characteristics and NT-proBNP category, we compared means and proportions using analysis of variance, followed by pairwise t-test and the chi-squared test, respectively. We calculated adjusted hazard ratios (HR) for stroke in the NT-proBNP groups using Cox modeling, with the NTproBNP $<30-p g / m L$ group as a reference. We then used natural $\log$ transformed (ln) NT-proBNP as a continuous variable because NT-proBNP had a positively skewed distribution. Covariates consisted of sex, age, body mass index (BMI), current smoking status, alcohol consumption, diabetes, hyperlipidemia, chronic kidney disease (CKD), systolic blood pressure, and use of antihypertensive drugs (fully adjusted model). For a sensitivity analysis, we further adjusted for habitual exercise and sleep time. Subsequently, we interpolated missing values of BMI $(n=27)$ from the regression slope on age after stratification for sex. For participants with unknown habitual exercise $(n=119)$ or daily sleep hours $(n=110)$, we set design variables coded 1 if the data were missing (data present $=0$ ), respectively. Given that NT-proBNP has been reported to predict stroke risk for 5 years, ${ }^{9}$ we stratified follow-up according to a 5-year period. The short-term predictive value of NTproBNP was assessed using HR, after setting the maximum follow-up period as 5 years. The long-term predictive value was assessed using HR, after censoring events observed during the initial 5 years. To weigh competing risks of death in the older population, the Cox model was fitted to a proportional sub-distribution hazards regression model, with weights for participants exposed to competing risks of death. Interactions were assessed by adding an interaction term to the Cox model. The influence of NT-proBNP on the discrimination of the model was determined by calculating the Uno's C-statistic using the Cox model, not considering competing risks. ${ }^{20}$ Statistical significance was determined as an $\alpha$-level $<0.05$ on 2 -sided test. Data are expressed as mean \pm SD unless otherwise noted. SAS version 9.4 (SAS Institute, Cary, NC, USA) was used for statistical analysis.

\section{Results}

\section{Characteristics}

The 1,198 participants (33.4\% men; mean age, $60.5 \pm 11.1$ years) consisted of $383(32.0 \%)$ with NT-proBNP $<30 \mathrm{pg} / \mathrm{mL}$; 340 (28.4\%) with NT-proBNP 30-54.9 pg/mL, $330(27.6 \%)$ with NT-proBNP 55.0-124.9 pg/mL; and 145 (12.1\%) with NT-proBNP $\geq 125.0 \mathrm{pg} / \mathrm{mL}$. Median NTproBNP was $43.3 \mathrm{pg} / \mathrm{mL}$ (IQR, $24.8-78.7 \mathrm{pg} / \mathrm{mL}$ ). Age, blood pressure, prevalence of alcohol consumption and hyperlipidemia or CKD, and the use of antihypertensive drugs consistently increased with increasing NT-proBNP ( $\mathrm{P} \leq 0.013$; Table 1). In contrast, BMI was inversely associated with higher NT-proBNP (Table 1).

\section{Stroke Incidence and Multivariable Adjusted Analysis}

During a median follow-up of 13.0 years (mean, 11.7 years), a first stroke occurred in 93 participants: 62 with cerebral infarction, 20 with intracerebral hemorrhage, and 11 with subarachnoid hemorrhage. During the follow-up, 19 participants moved away and were lost to follow-up; therefore, the follow-up rate was $98.4 \%$. Death as a competing risk occurred in 18 in the NT-proBNP $<30.0$ $\mathrm{pg} / \mathrm{mL}$ group, in 36 in the NT-proBNP $30.0-54.9-\mathrm{pg} / \mathrm{mL}$ group, in 39 in the NT-proBNP 55.0-124.9-pg/mL group, and in 42 in the NT-proBNP $\geq 125.0-p g / m L$ group.

The NT-proBNP category was significantly associated with stroke risk after adjustments for sex and age (trend $\mathrm{P}=0.042$ ), but was weakened to non-significance after further adjustments for other confounding factors (trend $\mathrm{P}=0.18$; Figure 2). When we set the maximum follow-up period as 5 years, even in the fully adjusted model, the participants with NT-proBNP $\geq 125.0 \mathrm{pg} / \mathrm{mL}$ had a significantly higher stroke risk than those with NT-proBNP $<30 \mathrm{pg} / \mathrm{mL}(\mathrm{P}=0.046$; Figure 2). In contrast, no significant associations were observed after censoring events during the initial 5 years (Figure 2). Similar results were observed when not considering the competing risks for death (Figure S1). We then further adjusted the model for habitual exercise and sleep time. Similar results were observed, although the significance of the HR of NT-proBNP $\geq 125.0 \mathrm{pg} / \mathrm{mL}$ during the initial 5 years was marginal 


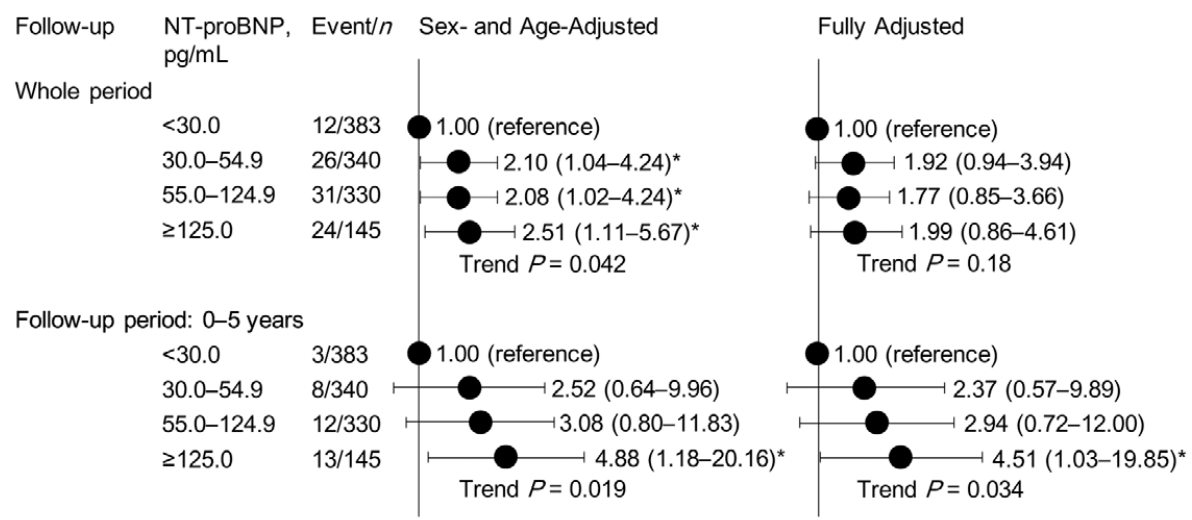

Follow-up period: 5 years-final (Events that occurred during the initial 5 years were censored)

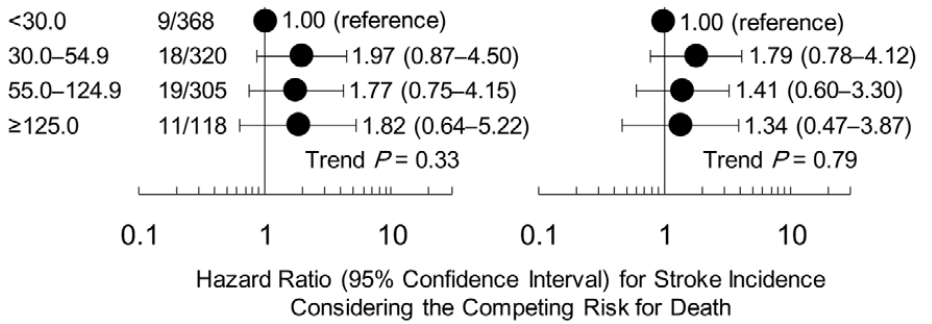

Figure 2. Adjusted $\mathrm{HR}(95 \% \mathrm{Cl})$ for stroke incidence estimated using the competing risk model to account for competing risks of death. In the fully adjusted model, the HR were adjusted for sex, age, body mass index, current smoking status, alcohol consumption, diabetes, hyperlipidemia, chronic kidney disease, systolic blood pressure, and use of antihypertensive drugs. $\mathrm{Cl}$, confidence intervals; HR, hazard ratios; NT-proBNP, N-terminal pro-B-type natriuretic peptide. ${ }^{*} \mathrm{P}<0.05$.

\section{$(\mathrm{P} \leq 0.053$; Figure S2).}

When we treated NT-proBNP as a continuous variable, a 1-SD increase in lnNT-proBNP was significantly associated with stroke risk $(\mathrm{P}=0.020$; Table 2$)$. Stratification analyses according to sex (men vs. women), age ( $<65$ vs. $\geq 65$ years), use of antihypertensive drugs, blood pressure level $(<140 /<90$ vs. $\geq 140 / \geq 90 \mathrm{mmHg})$, and CKD were also performed. Although no significant interactions between these factors and lnNT-proBNP regarding stroke risk were observed ( $\mathrm{P}$ for interaction $\geq 0.11$ ), the association of NT-proBNP with stroke risk during a follow-up period of $0-5$ years was noteworthy in men; in individuals not taking antihypertensive drugs; and in those without CKD (Table 2). Even if the definition of stroke was narrowed to ischemic stroke or hemorrhage, the association between $\operatorname{lnNT}$-proBNP and the risk for cerebral infarction or hemorrhage was not significant, similar to the association between total stroke risk and $\operatorname{lnNT}$-proBNP $(\mathrm{P} \geq 0.075$; Table S1).

We included $\ln N T$-proBNP $\times$ a time variable coded 1 for a follow-up period of $0-5$ years $(\geq 5$ years $=0)$ and also for a follow-up period $\geq 5$ years $(0-5$ years $=0)$ into the same model. Consequently, only the former time-dependent variable was significantly associated with an elevated stroke risk $(\mathrm{P}=0.017$ and $\mathrm{P}=0.27)$.

We evaluated other cut-offs of the follow-up period (Table 3). The HR per 1-SD increase in $\ln N T$-proBNP was $\geq 1.45$ when the maximum follow-up was set at 2-6 years. The HR became progressively lower with an extension of the maximum follow-up period from 7 up to 10 years. After the addition of $\operatorname{lnNT}$-proBNP, the accuracy of the
Uno's C-statistic tended to increase when extending the maximum follow-up period to 6 years, and decreased for a maximum follow-up period $\geq 7$ years, but never reached significance $(\mathrm{P} \geq 0.18)$.

\section{Discussion}

NT-proBNP was significantly and positively associated with an elevated stroke risk in the participants with no history of cardiovascular disease or AF, but the significance was detected only when the maximum follow-up period was set at 5 years. This suggests that NT-proBNP predicts 5-year but not long-term stroke risk in an Asian general population.

In the Hisayama cohort study (Japanese) with a follow-up of 5 years, the Iwate-Kenpoku cohort study (Japanese) with a follow-up of 2.8 years, and a Danish population study with a follow-up of 5 years, HR for stroke per 1-SD increase in $\ln N \mathrm{~T}$-proBNP or in BNP was $1.70-1.79 . .^{\mathbf{9} 21,22} \mathrm{~A}$ similar HR to these previous reports was observed in the present study, based on a follow-up period of $0-5$ years (Table 2). Meanwhile, a Rotterdam study with a mean follow-up of 9.3 years reported smaller HR for stroke risk, transient ischemic attack, and heart failure in 5,611 Europeans with no history of stroke; the HR for stroke per $1-\mathrm{SD}$ increase in NT-proBNP was 1.50 for men and 1.24 for women. ${ }^{23}$ These studies did not perform stratified analysis according to follow-up period, and did not take competing risks of death into account.,9,21,23 The present study, considering competing risks of death, is the first to show that, in an Asian general population, the predictive 


\begin{tabular}{|c|c|c|c|c|}
\hline Strata & Event / At risk & $\begin{array}{c}\text { HR }(95 \% \mathrm{Cl}) \text { for stroke per } 1-\mathrm{SD} \text { increase } \\
\text { in InNT-proBNP, considering } \\
\text { the competing risks for death }\end{array}$ & P-value & $\begin{array}{l}\text { P-value for } \\
\text { interaction }\end{array}$ \\
\hline \multicolumn{5}{|c|}{ Follow-up period: $0-5$ years } \\
\hline All & $36 / 1,198$ & $1.60(1.08-2.38)$ & 0.020 & - \\
\hline Sex & & & & 0.23 \\
\hline Men & $18 / 400$ & $1.86(1.14-3.02)$ & 0.013 & \\
\hline Women & $18 / 798$ & $1.35(0.67-2.72)$ & 0.40 & \\
\hline Age & & & & 0.11 \\
\hline$<65$ years & $13 / 755$ & $1.65(0.87-3.10)$ & 0.12 & \\
\hline$\geq 65$ years & $23 / 443$ & $1.57(0.93-2.65)$ & 0.091 & \\
\hline Antihypertensive drugs & & & & 0.42 \\
\hline Absent & $18 / 913$ & $1.93(1.10-3.40)$ & 0.023 & \\
\hline Present & $18 / 285$ & $1.26(0.71-2.23)$ & 0.43 & \\
\hline $\mathrm{BP} \geq 140 / \geq 90 \mathrm{mmHg}$ & & & & 0.75 \\
\hline Absent & $21 / 870$ & $1.39(0.87-2.22)$ & 0.17 & \\
\hline Present & $15 / 328$ & $1.84(0.99-3.44)$ & 0.055 & \\
\hline CKD & & & & 0.12 \\
\hline Absent & $29 / 1,091$ & $1.83(1.11-3.01)$ & 0.018 & \\
\hline Present & $7 / 107$ & $1.02(0.40-2.58)$ & 0.97 & \\
\hline \multicolumn{5}{|c|}{ Follow-up period: 5 years-final ${ }^{\dagger}$} \\
\hline All & $57 / 1,111$ & $1.13(0.83-1.55)$ & 0.43 & - \\
\hline Sex & & & & 0.28 \\
\hline Men & $25 / 359$ & $1.01(0.69-1.47)$ & 0.98 & \\
\hline Women & $32 / 752$ & $1.29(0.81-2.08)$ & 0.29 & \\
\hline Age & & & & 0.50 \\
\hline$<65$ years & $23 / 716$ & $1.37(0.80-2.33)$ & 0.25 & \\
\hline$\geq 65$ years & $34 / 395$ & $1.01(0.67-1.47)$ & 0.96 & \\
\hline Antihypertensive drugs & & & & 0.61 \\
\hline Absent & $27 / 857$ & $0.86(0.53-1.40)$ & 0.55 & \\
\hline Present & $30 / 254$ & $1.40(1.00-1.96)$ & 0.049 & \\
\hline $\mathrm{BP} \geq 140 / \geq 90 \mathrm{mmHg}$ & & & & 0.46 \\
\hline Absent & $28 / 818$ & $1.28(0.86-1.89)$ & 0.23 & \\
\hline Present & $29 / 293$ & $0.99(0.65-1.52)$ & 0.97 & \\
\hline CKD & & & & 0.27 \\
\hline Absent & $49 / 1,019$ & $1.15(0.83-1.60)$ & 0.39 & \\
\hline Present & $8 / 92$ & $0.90(0.41-1.97)$ & 0.79 & \\
\hline
\end{tabular}

1-SD increase in InNT-proBNP is 0.93 . tEvents that occurred during the initial 5 years were censored. BP, blood pressure; $\mathrm{Cl}$, confidence interval; HR, hazard ratio; In, log transformed; SD, standard deviation. Other abbreviations as in Table 1.

value of NT-proBNP was not statistically significant 5 years after the baseline measurement (Figure 2; Table 2).

In a previous meta-analysis, the association of NTproBNP or BNP with total cardiovascular risk was consistent when dividing the available studies according to a mean follow-up of 5 years. ${ }^{6}$ Three of 4 available studies, however, involved patients with median NT-proBNP $\geq 125.0 \mathrm{pg} / \mathrm{mL}$, suggesting that irreversible cardiac insufficiency might have contributed to the long-term prognostic value of NT-proBNP or BNP. ${ }^{6}$ In contrast, individuals with a history of cardiovascular disease or of AF were excluded from the present analysis. Median NT-proBNP in the present study was $43.3 \mathrm{pg} / \mathrm{mL}$. Therefore, NT-proBNP may not predict the long-term stroke risk in a population with no history of severe cardiac disease. Several studies have indicated associations between NT-proBNP and coronary artery calcium score, or carotid intima-media thickness. ${ }^{24,25}$ In the present study, mild cardiac dysfunction as well as potential atherosclerosis might be potential factors in the association between NT-proBNP and an elevated stroke risk. These mild impairments could be improved through lifestyle changes or treatment during follow-up, attenuating the predictive power of NT-proBNP. The time-dependent variables and various cut-off points of the follow-up period (Table 3) also implied a loss of predictive power of NT-proBNP for $>5$ years. Thus, NT-proBNP should be re-evaluated in a general population $\geq 5$ years following the previous measurement. A recent large-scale study involving Danish population-based medical registries reported a higher 30-year stroke risk in heart failure patients compared with a general population cohort, but the stroke risk in heart failure patients was clearest during $0-5$-year follow-up periods. ${ }^{26}$ This seems to support the present hypothesis, although the population and the exposure in that study differ from those in the present study. ${ }^{26}$ 


\begin{tabular}{|ccccc|}
\hline $\begin{array}{c}\text { Table 3. HR per 1-SD Increase in InNT-proBNP vs. Follow-up Length } \\
\text { Follow-up } \\
\text { period (years) }\end{array}$ & $\begin{array}{c}\text { Event / At risk } \\
\text { HR (95\%Cl) for stroke per 1-SD } \\
\text { increase in InT-proBNPt }\end{array}$ & $\begin{array}{c}\text { C-statistic of model including } \\
\text { only covariates }\end{array}$ & $\begin{array}{c}\text { Improvement in C-statistic (SE) } \\
\text { after addition of InNT-proBNP }\end{array}$ \\
$\geq 1$ & $7 / 1,198$ & $1.19(0.57-2.49)$ & 0.8683 & $0.0039(0.018)$ \\
$0-2$ & $86 / 1,180$ & $1.27(0.98-1.64)$ & 0.7717 & $0.0037(0.0072)$ \\
$\geq 2$ & $13 / 1,198$ & $1.66(0.71-3.89)$ & 0.8636 & $0.015(0.027)$ \\
$0-3$ & $80 / 1,167$ & $1.20(0.94-1.55)$ & 0.7680 & $0.0022(0.0063)$ \\
$\geq 3$ & $20 / 1,198$ & $1.46(0.82-2.60)$ & 0.8276 & $0.0043(0.021)$ \\
$0-4$ & $73 / 1,153$ & $1.22(0.93-1.59)$ & 0.7678 & $0.0029(0.0067)$ \\
$\geq 4$ & $27 / 1,198$ & $1.54(0.96-2.47)$ & 0.8015 & $0.0055(0.018)$ \\
$0-5$ & $66 / 1,133$ & $1.22(0.91-1.64)$ & 0.7751 & $0.0036(0.0066)$ \\
$\geq 5$ & $36 / 1,198$ & $1.60(1.08-2.38)$ & 0.7746 & $0.017(0.017)$ \\
$0-6$ & $57 / 1,111$ & $1.13(0.83-1.55)$ & 0.7741 & $0.0001(0.0052)$ \\
$\geq 6$ & $44 / 1,198$ & $1.55(1.06-2.26)$ & 0.7781 & $0.020(0.015)$ \\
$0-7$ & $49 / 1,097$ & $1.09(0.80-1.49)$ & 0.7755 & $0.0000(0.0036)$ \\
$\geq 7$ & $55 / 1,198$ & $1.38(0.99-1.91)$ & 0.7502 & $0.0121(0.012)$ \\
$0-8$ & $38 / 1,073$ & $1.15(0.79-1.67)$ & 0.8108 & $0.0003(0.0059)$ \\
$\geq 8$ & $62 / 1,198$ & $1.37(1.01-1.85)$ & 0.7612 & $0.0098(0.010)$ \\
$0-9$ & $31 / 1,054$ & $1.11(0.73-1.69)$ & 0.8065 & $0.0008(0.0082)$ \\
$\geq 9$ & $68 / 1,198$ & $1.35(1.02-1.79)$ & 0.7561 & $0.0064(0.0091)$ \\
$0-10$ & $25 / 1,027$ & $1.07(0.67-1.73)$ & 0.8247 & $0.0000(0.0071)$ \\
$\geq 10$ & $74 / 1,198$ & $1.31(1.00-1.71)$ & 0.7660 & $0.0045(0.0074)$ \\
\hline
\end{tabular}

1-SD increase in InNT-proBNP is 0.93. Covariates were sex, age, BMI, current smoking status, alcohol consumption, diabetes, hyperlipidemia, CKD, SBP, and use of antihypertensive drugs. tHR were calculated using a Cox model considering competing risks. ${ }^{\circ} \mathrm{C}$-statistics were calculated using a model without considering competing risks for death. Abbreviations as in Tables 1,2.

In the present study, the stroke risk in the group with NT-proBNP $\geq 125.0 \mathrm{pg} / \mathrm{mL}$ was significantly higher than that in the NT-proBNP $<30$-pg/mL group but not for that in the NT-proBNP $30-54.9-\mathrm{pg} / \mathrm{mL}$ group. According to the present study, NT-proBNP $<30 \mathrm{pg} / \mathrm{mL}$ might be recognized as optimal in terms of cardiovascular risk stratification, if we set a new threshold of NT-proBNP. In another study based on 3,798 middle-aged participants with no history of coronary artery disease, congestive heart failure, and hypertension, the participants with NT-proBNP $\geq 99.5 \mathrm{pg} / \mathrm{mL}$ had a 1.24 -fold higher risk of hypertension compared with participants with NT-proBNP $<28.5 \mathrm{pg} / \mathrm{mL} .^{27}$ This raises the possibility that hypertension during follow-up might have contributed to the present results, and appears to support the present suggestion that NT-proBNP $<30 \mathrm{pg} / \mathrm{mL}$ is optimal.

The association of NT-proBNP with stroke risk during a follow-up of 0-5 years remained significant in men; in individuals not taking antihypertensive drugs; and in those without CKD (Table 2). In the Iwate-Kenpoku Cohort study, based on a general population (mean age, 62.7 years), the HR for ischemic stroke per 1-SD increment in InBNP was 1.70 in men and 1.69 in women, with no apparent sex difference in the predictive value of BNP. ${ }^{21}$ As mentioned, however, the Rotterdam study noted a higher HR for stroke in men than for women. ${ }^{23}$ The present findings are similar to those from the Rotterdam study. Although the interaction between sex and InNT-proBNP did not reach a significant level in either the present study or the Rotterdam study, ${ }^{23}$ estrogen, which promotes anti-atherosclerotic $^{28}$ or other sex-related differences, might weaken the prognostic significance of NT-proBNP. In the present study, the association of NT-proBNP with an increased risk for stroke was observed in participants not undergoing antihypertensive treatment and in those without CKD. Kidney dysfunction as well as antihypertensive drug treatment can affect NT-proBNP.1-4,13 Thus, sex, kidney function, and the use of antihypertensive drugs should be considered when assessing the effect or the predictive value of NT-proBNP.

The present study needs to be interpreted in the context of its potential limitations. First, given that the present subjects consisted of middle-aged-elderly Japanese residents, it is not clear whether the present results can be generalized to younger subjects. The current findings might not be generalizable to other ethnicities because, for example, myocardial infarction, and not stroke, is the overriding cardiovascular complication in Western populations. As discussed, however, the present results are similar to those from the Rotterdam study. ${ }^{23}$ It is possible that the association of NT-proBNP with stroke in Japanese individuals would not differ from that in those of European ethnicity, for example. Second, treatment started during follow-up or recent progress in medical technology might have attenuated the long-term predictive value of NT-proBNP in the present study, because the study began in 1997. The hypertension treatment rate increased 2-fold between 1990 and $2010,{ }^{29}$ implying that individuals with high NT-proBNP might have received some treatment, especially in those surviving 5 years after the baseline measurement. This might attenuate the prognostic power of NT-proBNP. Third, the small number of events limits the chances of a definitive conclusion. Because the limited number of events might also weaken the statistical power of the C-statistics, further studies based on a larger sample size are needed. Meanwhile, the improvement in the C-statistic by adding 
NT-proBNP in previous studies was similar to that based on a follow-up period of $0-5$ years in the present study (Table 3). ${ }^{9,30}$ The C-statistic for cardiovascular disease prediction increased by 0.021 in the Hisayama study and by 0.016 in the German study after adding NT-proBNP to the base model.9.30

\section{Conclusions}

Participants with NT-proBNP $\geq 125.0 \mathrm{pg} / \mathrm{mL}$ had a higher stroke risk than those with NT-proBNP $<30 \mathrm{pg} / \mathrm{mL}$ during the follow-up period of $0-5$ years. For other follow-up period cut-offs, however, the predictive power of NTproBNP for stroke decreased with the number of years after the NT-proBNP examination. This suggests that NT-proBNP should be re-evaluated periodically in Asian populations.

\section{Acknowledgments}

We are grateful to the residents and staff members in Ohasama and staff members of the Hanamaki City Government, Ohasama Hospital, Iwate Prefectural Stroke Registry, General Hanamaki Hospital, Teikyo University, Tohoku Medical and Pharmaceutical University, and Tohoku University for their valuable support on the Ohasama study project.

\section{Author Contributions}

M.S. wrote the first draft of this manuscript. All authors conducted the Ohasama study and commented on the manuscript, and approved the final manuscript.

\section{Sources of Funding}

This study was supported by Grants for Scientific Research (16H05243, 16H05263, 16K09472, 16K11850, 16K15359, 17H04126, $17 \mathrm{H} 06533,17 \mathrm{~K} 15853,17 \mathrm{~K} 19930,18 \mathrm{~K} 09674,18 \mathrm{~K} 09904$, and 18K17396), Culture, Sports, Science, and Technology, Japan; Grantin-Aid for Young Scientists of Showa Pharmaceutical University H28-4; the Japan Arteriosclerosis Prevention Fund; Comprehensive Research on Cardiovascular and Life-Style Related Diseases (H26-Junkankitou [Seisaku]-Ippan-001) and (H29-JunkankitouIppan-003) from the Ministry of Health, Labor, and Welfare; and A Scheme to Revitalize Agriculture and Fisheries in Disaster Area through Deploying Highly Advanced Technology (NouEi 2-02) from the Ministry of Agriculture, Forestry and Fisheries, Japan; academic contributions from Pfizer Japan Inc.; and scholarship donations from Chugai Pharmaceutical Co., Ltd. and Daiichi Sankyo Co., Ltd.

\section{Disclosures}

The authors declare no conflicts of interest.

\section{References}

1. Takase H, Dohi Y, Toriyama T, Okado T, Tanaka S, Sato K, et al. Does B-type natriuretic peptide predict the new onset of hypertension? Hypertens Res 2008; 31: 1737-1744.

2. Ribeiro AL. Natriuretic peptides in elderly people with acute myocardial infarction. BMJ 2009; 338: b787.

3. Morrow DA, Cannon CP, Jesse RL, Newby LK, Ravkilde J, Storrow AB, et al. National Academy of Clinical Biochemistry Laboratory Medicine Practice Guidelines: Clinical characteristics and utilization of biochemical markers in acute coronary syndromes. Circulation 2007; 115: e356-e375.

4. Freitag MH, Larson MG, Levy D, Benjamin EJ, Wang TJ, Leip EP, et al. Plasma brain natriuretic peptide levels and blood pressure tracking in the Framingham Heart Study. Hypertension 2003; 41: 978-983.

5. Seino Y, Ogawa A, Yamashita T, Fukushima M, Ogata K, Fukumoto H, et al. Application of NT-proBNP and BNP measurements in cardiac care: A more discerning marker for the detection and evaluation of heart failure. Eur J Heart Fail 2004; 6: $295-300$.

6. Di Angelantonio E, Chowdhury R, Sarwar N, Ray KK, Gobin R,
Saleheen D, et al. B-type natriuretic peptides and cardiovascular risk: Systematic review and meta-analysis of 40 prospective studies. Circulation 2009; 120: 2177-2187.

7. Lawes CM, Rodgers A, Bennett DA, Parag V, Suh I, Ueshima $\mathrm{H}$, et al. Blood pressure and cardiovascular disease in the Asia Pacific region. J Hypertens 2003; 21: 707-716.

8. Ueshima H, Sekikawa A, Miura K, Turin TC, Takashima N, Kita Y, et al. Cardiovascular disease and risk factors in Asia: A selected review. Circulation 2008; 118: 2702-2709.

9. Doi Y, Ninomiya T, Hata J, Hirakawa Y, Mukai N, Ikeda F, et al. N-terminal pro-brain natriuretic peptide and risk of cardiovascular events in a Japanese community: The Hisayama study. Arterioscler Thromb Vasc Biol 2011; 31: 2997-3003.

10. Geng Z, Huang L, Song M, Song Y. N-terminal pro-brain natriuretic peptide and cardiovascular or all-cause mortality in the general population: A meta-analysis. Sci Rep 2017; 7: 41504.

11. Ohkubo T, Asayama K, Kikuya M, Metoki H, Hoshi H, Hashimoto J, et al. How many times should blood pressure be measured at home for better prediction of stroke risk?: Ten-year follow-up results from the Ohasama study. J Hypertens 2004; 22: 1099-1104.

12. Hara A, Ohkubo T, Kikuya M, Shintani Y, Obara T, Metoki H, et al. Detection of carotid atherosclerosis in individuals with masked hypertension and white-coat hypertension by selfmeasured blood pressure at home: The Ohasama study. $J$ Hypertens 2007; 25: 321-327.

13. Satoh M, Hosaka M, Asayama K, Kikuya M, Inoue R, Metoki $\mathrm{H}$, et al. Association between N-terminal proB-type natriuretic peptide and day-to-day blood pressure and heart rate variability in a general population: The Ohasama study. J Hypertens 2015; 33: $1536-1541$.

14. Kristensen SL, Jhund PS, Mogensen UM, Rorth R, Abraham WT, Desai A, et al. Prognostic value of N-terminal pro-B-type natriuretic peptide levels in heart failure patients with and without atrial fibrillation. Circ Heart Fail 2017; 10: e004409.

15. Kuzuya T, Nakagawa S, Satoh J, Kanazawa Y, Iwamoto Y, Kobayashi M, et al. Report of the Committee on the classification and diagnostic criteria of diabetes mellitus. Diabetes Res Clin Pract 2002; 55: 65-85.

16. Imai Y, Nishiyama A, Sekino M, Aihara A, Kikuya M, Ohkubo $\mathrm{T}$, et al. Characteristics of blood pressure measured at home in the morning and in the evening: The Ohasama study. J Hypertens 1999; 17: 889-898.

17. Satoh M, Kikuya M, Hosaka M, Asayama K, Inoue R, Metoki H, et al. Association of aldosterone-to-renin ratio with hypertension differs by sodium intake: The Ohasama study. Am J Hypertens 2015; 28: $208-215$.

18. Special report from the National Institute of Neurological Disorders and Stroke. Classification of cerebrovascular diseases III. Stroke 1990; 21: 637-676.

19. McMurray JJ, Adamopoulos S, Anker SD, Auricchio A, Bohm M, Dickstein K, et al. ESC Guidelines for the diagnosis and treatment of acute and chronic heart failure 2012: The Task Force for the Diagnosis and Treatment of Acute and Chronic Heart Failure 2012 of the European Society of Cardiology. Developed in collaboration with the Heart Failure Association (HFA) of the ESC. Eur Heart $J$ 2012; 33: 1787-1847.

20. Uno H, Cai T, Pencina MJ, D'Agostino RB, Wei LJ. On the $\mathrm{C}$-statistics for evaluating overall adequacy of risk prediction procedures with censored survival data. Stat Med 2011; 30: $1105-1117$.

21. Takahashi T, Nakamura M, Onoda T, Ohsawa M, Tanno K, Itai K, et al. Predictive value of plasma B-type natriuretic peptide for ischemic stroke: A community-based longitudinal study. Atherosclerosis 2009; 207: 298-303.

22. Kistorp C, Raymond I, Pedersen F, Gustafsson F, Faber J, Hildebrandt P. N-terminal pro-brain natriuretic peptide, $\mathrm{C}$-reactive protein, and urinary albumin levels as predictors of mortality and cardiovascular events in older adults. JAMA 2005; 293: $1609-1616$.

23. Portegies ML, Kavousi M, Leening MJ, Bos MJ, van den Meiracker AH, Hofman A, et al. N-terminal pro-B-type natriuretic peptide and the risk of stroke and transient ischaemic attack: The Rotterdam Study. Eur J Neurol 2015; 22: 695-701.

24. Abdullah SM, Khera A, Das SR, Stanek HG, Canham RM, Chung AK, et al. Relation of coronary atherosclerosis determined by electron beam computed tomography and plasma levels of n-terminal pro-brain natriuretic peptide in a multiethnic population-based sample (the Dallas Heart Study). Am J Cardiol 2005; 96: $1284-1289$. 
25. Pastormerlo LE, Maffei S, Latta DD, Chubuchny V, Susini C, Berti $\mathrm{S}$, et al. N-terminal proB-type natriuretic peptide is a marker of vascular remodelling and subclinical atherosclerosis in asymptomatic hypertensives. Eur J Prev Cardiol 2016; 23: $366-376$.

26. Adelborg K, Szepligeti S, Sundboll J, Horvath-Puho E, Henderson VW, Ording A, et al. Risk of stroke in patients with heart failure: A population-based 30-year cohort study. Stroke 2017; 48: 1161-1168.

27. Bower JK, Lazo M, Matsushita K, Rubin J, Hoogeveen RC, Ballantyne CM, et al. N-terminal pro-brain natriuretic peptide (NT-proBNP) and risk of hypertension in the Atherosclerosis Risk in Communities (ARIC) Study. Am J Hypertens 2015; 28: $1262-1266$.

28. Arnal JF, Gourdy P, Elhage R, Garmy-Susini B, Delmas E, Brouchet L, et al. Estrogens and atherosclerosis. Eur J Endocrinol 2004; 150: 113-117.

29. Miura K, Nagai M, Ohkubo T. Epidemiology of hypertension in Japan: Where are we now? Circ J 2013; 77: 2226-2231.
30. Kara K, Lehmann N, Neumann T, Kalsch H, Mohlenkamp S, Dykun I, et al. NT-proBNP is superior to BNP for predicting first cardiovascular events in the general population: The Heinz Nixdorf Recall Study. Int J Cardiol 2015; 183: 155-161.

\section{Supplementary Files}

\section{Supplementary File}

Figure S1. Adjusted HR (95\% CI) for stroke incidence.

Figure S2. Adjusted HR (95\% CI) for stroke incidence estimated using the competing risk model to account for competing risks of death.

Table S1. lnNT-proBNP and the risk for ischemic stroke or hemorrhage $(n=1,198)$

Please find supplementary file(s);

http://dx.doi.org/10.1253/circj.CJ-17-1227 